\title{
Optimalisasi Germas Melalui Kader 'Aisyiyah dalam Program Eliminasi Tuberculosis Pasca Terapi TB
}

\author{
1 Ana Majdawati*, 2Inayati \\ 1 Radiologi, Prodi Kedokteran FKIK Universitas Muhammadiyah Yogyakarta \\ 2 Mikrobiologi, Prodi Kedokteran FKIK Universitas Muhammadiyah Yogyakarta \\ Prodi Kedokteran, FKIK UMY, Kampus Terpadu UMY, Jl Brawijaya, Taman Tirto, Kasihan, Bantul 55183, Hp 081578095245 \\ Email : anamjdwt2@gmail.com \\ DOI: $10.18196 / \mathrm{ppm} .36 .310$
}

\begin{abstract}
Abstrak
Pasca-TB adalah istilah untuk pasien Tuberkulosis (TB) yang pernah mendapat Obat Anti TB (OAT) dan dinyatakan sembuh. Evaluasi dilakukan karena pelvang relaps 5-10x, timbulnya TB resisten obat, dan Sindroma Obstruksi Pasca-TB (SOPT) pada pasien pasca-TB. Data menunjukkan 56,41\% pasca-TB masih bergejala dan 88,5\% temuan lesi radiografi toraks dan terbanyak fibrosis $78,2 \%$. Angka kejadian TB di Kecamatan Mergangsan Yogyakarta cukup tinggi dengan pemukiman padat. Pengabdian masyarakat ini melibatkan kader TB 'Aisyiyah yang sudah bekerjasama dengan puskesmas terkait TB di masyarakat. Hasil wawancara awal, kendala yang ditemui di lapangan: 1). kader TB 'Aisyiyah sebatas penemuan kasus TB baru, evaluasi pasien pasca-TB jarang dilakukan; 2) kurangnya pemahaman dan perlunya refreshing TB, pasca-TB dan komplikasinya; 3). Keterbatasan komunikasi. Tujuan pengabdian masyarakat ini mengoptimalkan tugas dan peran kader TB 'Aisyiyah pada kasus TB yang meliputi evaluasi pasien pasca-TB. Kegiatan yang dilakukan, sosialisasi pengabdian masyarakat berdasarkan Focus Group Discussion (FGD), pelatihan pengisian lembar investigasi pasca-TB. Kegiatan tatap muka masa pandemik Covid 19 dibatasi 11 wakil kader yang selanjutnya dapat meneruskan ilmunya kepada masyarakat. Bukti keberhasilan pengabdian masyarakat adalah hasil pengisian lembar investigasi oleh kader yang lengkap serta pasien pasca-TB yang bersedia melanjutkan pemeriksaan sebanyak 54 orang.
\end{abstract}

Kata kunci : kader TB "Aisyiyah, pasien pasca-TB, evaluasi pasca-TB, lembar investigasi.

\section{Pendahuluan}

Tuberkulosis (TB) di Indonesia 3 tahun terakhir ini menunjukkan angka kesembuhan yang meningkat, yaitu 85\%. Peningkatan ini sayangnya tidak disertai evaluasi pasien pasca-TB, yaitu pasien yang dinyatakan sembuh setelah pemberian Obat Anti TB (OAT) lengkap. Hal ini menyebabkan timbulnya berbagai masalah, yaitu peningkatann TB Resistan Obat (TB RO) (44.000 kasus yang terdiri 2,4\% kasus baru dan 13\% pasca-TB) (Situasi TB Indonesia, 2018; TB Kemenkes, 2018; Afifa and Pakasi, 2015). Data penelitian menunjukkan 56,41\% pasien pasca-TB masih memiliki gejala klinis TB dan $88,5 \%$ memiliki sequele dari radiografi toraks (fibrosis 78,2\%). Sequele ini kadang menimbulkan gejala batuk berdahak/darah, sesak nafas dan nyeri dada yang berdampak terhadap kebugaran tubuh disebut Sindroma Obstruksi PascaTB (SOPT). Pasien pasca-TB berpeluang 5-10 kali relaps/kambuh, empat kali lipat resisten, dan sepuluh kali lipat MDR TB (Mbatchou Ngahane et al., 2016; Naomi et al., 2016).

Kecamatan Mergangsan merupakanan pemukiman padat no.2 di Yogyakarta, dengan kejadian TB cukup tinggi dibanding kecamatan yang lain (tahun 2004 - 2010). Pelaksanaan pengabdian masyarakat ini di Kecamatan Mergangsan yang terdiri dari Kelurahan Brontokusuman, Keparakan, dan Wirogunan. Rata-rata usia terbanyak adalah usia produktif 1564 tahun (22.761 jiwa dari seluruh penduduk yaitu 31,948 jiwa (71\%) (Chrysantina et al., 2004; "Data Dinas kesehatan Yogyakarta, 2018; Naomi et al., 2016.). Jumlah kasus TB di Kecamatan Mergangsan adalah 46 (tahun 2013-2016) (Naomi et al., 2016.) Upaya penaggulangan TB terus dilakukan oleh Muhammadiyah melalui kader TB care-Aisyiyah sejak tahun 2002 dengan penemuan kasus, pendampingan pasien TB dan keluarganya. Kader TB 'Aisyiyah menjadi mediator, motivator antara masyarakat dengan pusat layanan kesehatan tingkat dasar (puskesmas setempat) (Data Dinas kesehatan Yogyakarta, 2018; Pasaribu, 2018; Riyadi, 2018). 
Penanggulangan TB di Kecamatan Mergangsan secara umum cukup baik, beberapa hal yang perlu diperhatikan terkait kasus TB di Kecamatan Mergangsan: 1). Masih tingginya kejadian TB, 2). Follow up terhadap kinerja dan motivasi kader TB 'Aisyiyah masis belum optimal (40-60\%), 3). Pengelolaan dan Evaluasi pasien pasca-TB yang belum dilakukan, terkait: lingkungan keluarga dan masyarakat, kejiwaan, komplikasi, tempat tinggal yang padat dan minim sinar matahari. Sindroma obstruksi pasca-TB (SOPT) (10, 11-13) Adriztina, I et al., 2016; Fadhilah et al., 2014).

Tujuan pengabdian masyarakat ini: a) Menyampaikan permasalahan TB dan pasca-TB berdasarkan data dan tindak lanjutnya b). Optimalisasi peran kader dengan refreshing, diskusi, tanya jawab dan solusi yang dirumuskan bersama. Kegiatan ini dilaksanakan dengan metode ceramah, diskusi kelompok kecil terkait $\mathrm{TB}$, permasalahan dan tindaklanjutnya dengan Focus Group Discussion (FGD); 3). Kader TB 'Aisyiyah melakukan pendataan terhadap kasus pascaTB, kondisi rumah, lingkungan dan keluarga inti yang kontak dengan pasien pasca-TB. Pendataan pasien pasca-TB menggunakan lembar checklist/investigasi yang sudah dibuat oleh tim pengabdian masyarakat dengan pelatihan komunikasi yang baik dan nyaman antara kader dengan penderita pasca-TB (Pasaribu, 2018; Riyadi, 2018).

\section{Metode Pelaksanaan}

Metode pelaksanaan kegiatan pengabdian masyarakat ini, berdasarkan atas beberapa permasalahan terhadap kasus TB di Kecamatan Mergangsan yang terdiri dari 3 Kelurahan, yaitu Brontokusuman, Wirogunan dan Keparakan. Metode pelaksanaan mengikutsertakan perangkat desa dan petugas psukesmas serta peran serta kader TB 'Aisyiyah sebagai central pelaksanaan pengabdian masyarakat tentang "Optimalisasi Germas melalui Kader "Aisyiyah dalam Program Eliminasi Tuberculosis pasca terapi TB”

Metode Pelaksanaan Pengabdian masyarakat :

1. Pengumpulan informasi data wilayah Kecamatan Mergangsan, terkait data TB, kendala dan permasalahannya. Informasi dari Kepala Desa di wilayah Mergangsan , Kader TB 'Aisyiyah, Pengurus TB Puskesmas Mergangsan

2. Sosialisasi tujuan pengabdian masyarakat kepada kader TB 'Aisyiyah, Kepala Desa dan Pengurus TB puskesmas Mergangsan

3. Diskusi kelompok kecil terkait : temuan kasus, kendala dan solusi yang ditawarkan

4. Refreshing: materi TB (penemuan kasus pasca-TB, kepentingan evaluasi dilakukan dan komplikasi yang mungkin terjadi, pelatihan Teknik Komunikasi kader TB 'Aisyiyah dengan pasien pasca-TB dan keluarga yang efektif dan nyaman)

5. Temuan kasus dengan pengisian data investigasi/kuesioner dan tindak lanjut atau pengantar kepada temuan kasus pasca-TB

6. Rekapitulasi dan Analisis hasil investigasi dan rencana tindak lanjut hasil temuan kasus pasien pasca-TB 


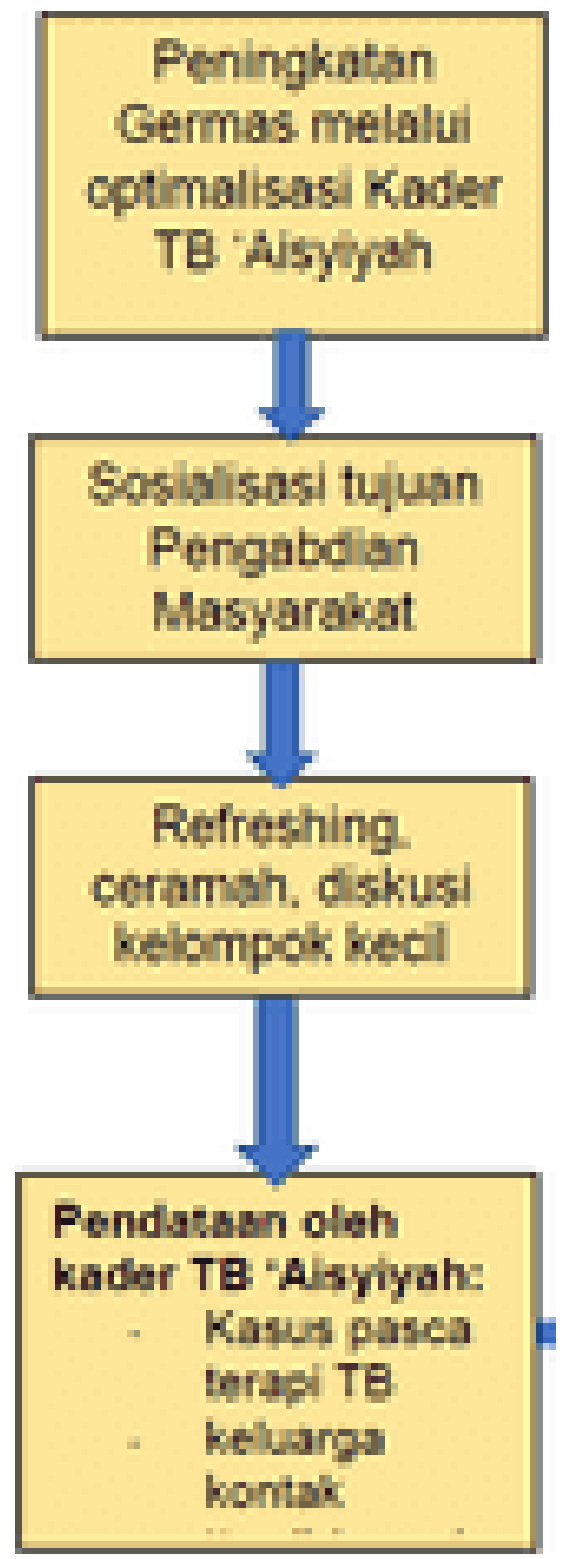

Gambar 1. Alur Metode Pelaksanaan Pengabdian Masyarakat

Tabel 1. Permasalahan dan Metode pelaksanaan Pengabdian Masyarakat

\begin{tabular}{|c|c|c|c|c|}
\hline No & $\begin{array}{l}\text { Permasalahan TB di Kecamatan } \\
\text { Mergangsan, Yogyakarta }\end{array}$ & Metode Pelaksanaan & Sasaran & Pelaksana \\
\hline 1 & $\begin{array}{l}\text { Kasus TB di Kecamatan } \\
\text { Mergangsan yang cukup tinggi, } \\
\text { di Yogyakarta }\end{array}$ & $\begin{array}{l}\text { Sosialisasi data TB di } \\
\text { Kecamatan Mergangsan } \\
\text { (Data TB Wilayah DIY) } \\
\text { kepada }\end{array}$ & $\begin{array}{l}\text { Sasaran : } \\
\text { - kader TB ‘Aisyiyah, } \\
\text { - petugas Puskesmas } \\
\text { Mergangsan } \\
\text { - Kepala Desa di } \\
\text { Kecamatan Mergangsan }\end{array}$ & $\begin{array}{l}\text { - Tim Pengabdian Masyarakat } \\
\text { LP3M FKIK UMY } \\
\text { - Admin }\end{array}$ \\
\hline 2 & $\begin{array}{l}\text { Peran Kader TB ‘Aisyiyah yang } \\
\text { masih kurang optimal, akibat } \\
\text { refreshing materi TB yang } \\
\text { berkaitan dengan pentingnya } \\
\text { evaluasi pasca-TB dan } \\
\text { tindaklanjutnya yang masih } \\
\text { kurang atau belum pernah } \\
\text { diberikan serta motivasi kader }\end{array}$ & $\begin{array}{l}\text { Melakukan Diskusi, tanya } \\
\text { jawab serta solusi pemecahan } \\
\text { masalah dengan metode } \\
\text { Diskusi kelompok kecil } \\
\text { (Focus Group } \\
\text { Disvcussion/FGD) Ceramah } \\
\text { pemberian materi, pelatihan } \\
\text { komunikasi yang efektif dan }\end{array}$ & $\begin{array}{l}\text { - Perwakilan Kader TB } \\
\text { Aisyiyah Kecamatan } \\
\text { Mergangsan (3-4 kader/ } \\
\text { kelurahan) } \\
\text { - Ketua kader 'Aisyiyah } \\
\text { Cabang Mergangsan } \\
\text { - Petugas Puskesmas } \\
\text { Mergangsan }\end{array}$ & $\begin{array}{l}\text { - Tim Pengabdian Masyarakat } \\
\text { LP3M FKIK UMY } \\
\text { - Bpk Muhammad Arif Rizki, } \\
\text { M.Psi } \\
\text { - Admin }\end{array}$ \\
\hline
\end{tabular}




\begin{tabular}{|c|c|c|c|c|}
\hline No & $\begin{array}{l}\text { Permasalahan TB di Kecamatan } \\
\text { Mergangsan, Yogyakarta }\end{array}$ & Metode Pelaksanaan & Sasaran & Pelaksana \\
\hline & $\begin{array}{l}\text { yang menurun karena kesibukan } \\
\text { yang dijalani sehari-hari, } \\
\text { kendala komunikasi dengan } \\
\text { pasien TB dan keluarga }\end{array}$ & nyaman & & \\
\hline 3 & $\begin{array}{l}\text { Data kondisi Kesehatan pasien } \\
\text { pasca-TB di Kecamatan } \\
\text { Mergangsan }\end{array}$ & $\begin{array}{l}\text { Membuat "lembar/ form } \\
\text { Investigasi“ berdasarkan } \\
\text { lembar isian TB dari } \\
\text { puskesmas dengan } \\
\text { melakukan perbaikan dan } \\
\text { penambahan hal-hal yang } \\
\text { diperlukan sebagai } \\
\text { kelengkapan data } \\
\text { Pengisian lembar investigasi } \\
\text { pasien pasca-TB }\end{array}$ & $\begin{array}{l}\text { - Kader TB ‘Asyiyah } \\
\text { yang telah diberi } \\
\text { refreshing TB dan cara } \\
\text { pengisian lembar } \\
\text { investigasi dan pelatihan } \\
\text { komunikasi } \\
\text { - Pasien pasca-TB yang } \\
\text { bersedia }\end{array}$ & $\begin{array}{l}\text { - Tim Pengabdian Masyarakat } \\
\text { LP3M FKIK UMY } \\
\text { - Admin }\end{array}$ \\
\hline
\end{tabular}

\section{Hasil dan Pembahasan}

Pengabdian masyarakat yang berjudul "Optimalisasi Germas melalui Kader 'Aisyiyah dalam Program Eliminasi Tuberculosis pasca terapi TB" dapat terlaksana dengan baik dan lancar. Pengabdian ini mundur dari waktu yang direncanakan terkait Pandemi Covid19 pada Maret 2020. Kegiatan diawali sosialisasi kepada kader Selasa, 30 Juni 2020 di Gedung RW 19, Kelurahan Brontokusuman dengan membatasi jumlah kader hanya 7 orang. Kader yang dipilih yang senior dan berpengalaman dan mewakili 3 kelurahan di Kecamatan Mergangsan. Harapannya kader utama ini dapat mengoordinasi kader yang lain di wilayahnya untuk melakukan program selanjutnya.

Acara sosialisasi yang dilakukan, yaitu informasi kejadian TB yang masih tinggi di Kecamatan Mergangsan dan diskusi kelompok atau Focus Group Discussion (FGD). Beberapa temuan di lapangan yang didapatkan dari hasil diskusi dengan kader adalah, yaitu:

1. Terkait pasien pasca-TB

1.1. sulitnya melakukan komunikasi dengan pasien pasca-TB karena mereka merasa sudah sembuh, dan tidak perlu dilakukan evaluasi lagi karena dianggap merepotkan dan menghabiskan waktu saja,

1.2. Anggapan yang salah pada pasien pasca-TB yang merasa kalau sudah sembuh dan pernah diobati tidak akan kambuh lagi,

1.3. Pasien pasca-TB tidak mengetahui bahwa pada pasien pasca-TB mempunyai risiko 5-10 kali lipat untuk relaps atau kambuh dibanding pasien non-TB,

1.4. Pengetahuan yang rendah tentang komorbid atau faktor risiko yang menyebabkan mudah relaps atau kambuh pada pasien pasca-TB.

2. Terkait Kader TB 'Aisyiyah

2.1. Peran kader TB 'Aisyiyah yang kurang optimal terkait evaluasi pasien pasca-TB

2.2. Refreshing ilmu dan pengetahuan terkait pentingnya evaluasi dan tindak lanjut terhadap temuan kasus pasca-TB

2.3. Kurangnya pengetahuan tentang ralaps pasien pasca-TB, komplikasi dan usaha prefentif. 


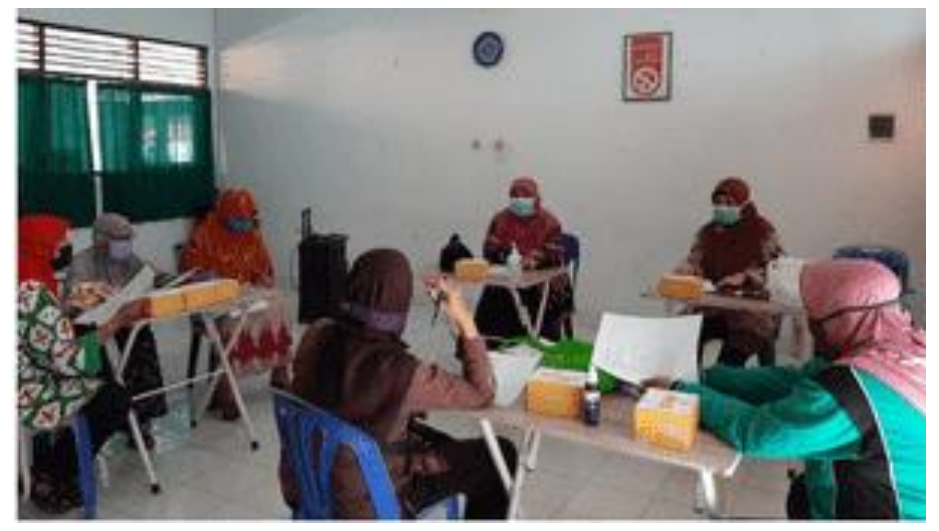

Gambar. 1. Sosialisasi Pengabdian Masyarakat kepada kader TB ‘Aisyiyah Kecamatan Mergangsan dihadiri wakil dari 3 Kelurahan (Brontokusuman, Keparakan dan Wirogunan)

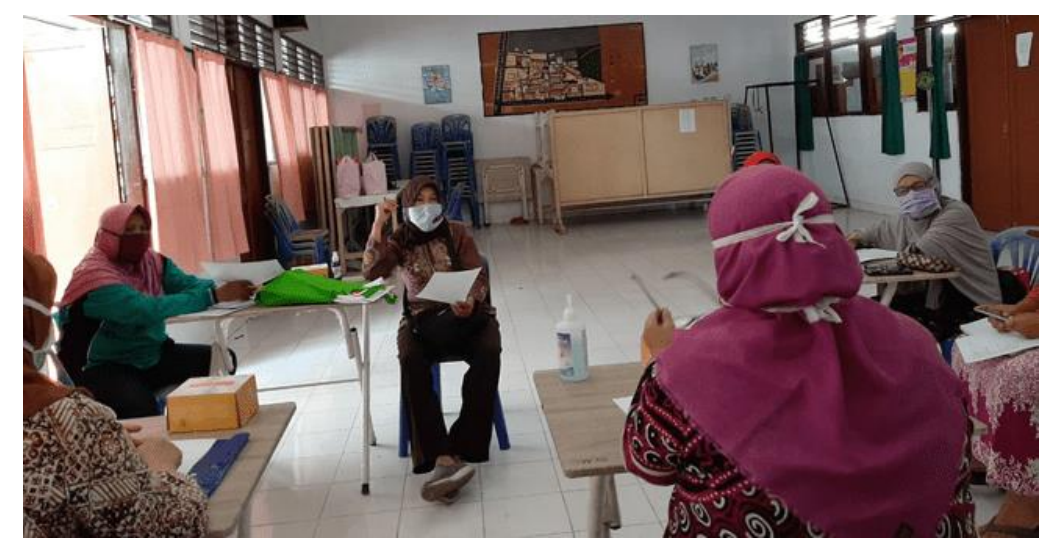

Gambar 2. Focus Group Discussion (FGD) yang merumuskan beberapa temuan dan kendala di lapangan oleh kader TB 'Aisyiyah Kecamatan Mergangsan

Tindak lanjut terhadap temuan pertemuan pertama, adalah:

1. Menyusun lembar investigasi pasien pasca-TB yang berisi data klinis dan kondisi lingkungan.

2. Pertemuan dengan kader dengan materi pelatihan wawancara efektif terkait pengisian lembar investigasi dan refreshing permasalahan pasca-TB

Pertemuan yang kedua dilaksanakan Selasa 21 Juli 2020 jam 13.00-15.00 di Kafe 1912 Universitas Muhammadiyah Yogyakarta. Acara ini diisi oleh 2 pemateri, Seputar Pasien PascaTB: 1). Materi pentingnya evaluasi pasca-TB, faktor risiko kekambuhan, usaha prefentif dan komplikasi pasca-TB; 2). Bagaimana melakukan pendataan gejala klinis, kondisi lingkungan pasien pasca-TB dan penjelasan form investigasi pasien pasca-TB oleh dr Ana Majdawati, M.Sc., Sp.Rad (K); 2) Trik wawancara pada pasien pasca-TB, aspek psikologis dan mental oleh M.Arif Rizki., M.Psi, Psikolog dan Tindak lanjut pemeriksaan TB dengan sputum oleh dr Inayati., M.Kes., Sp.MK. 


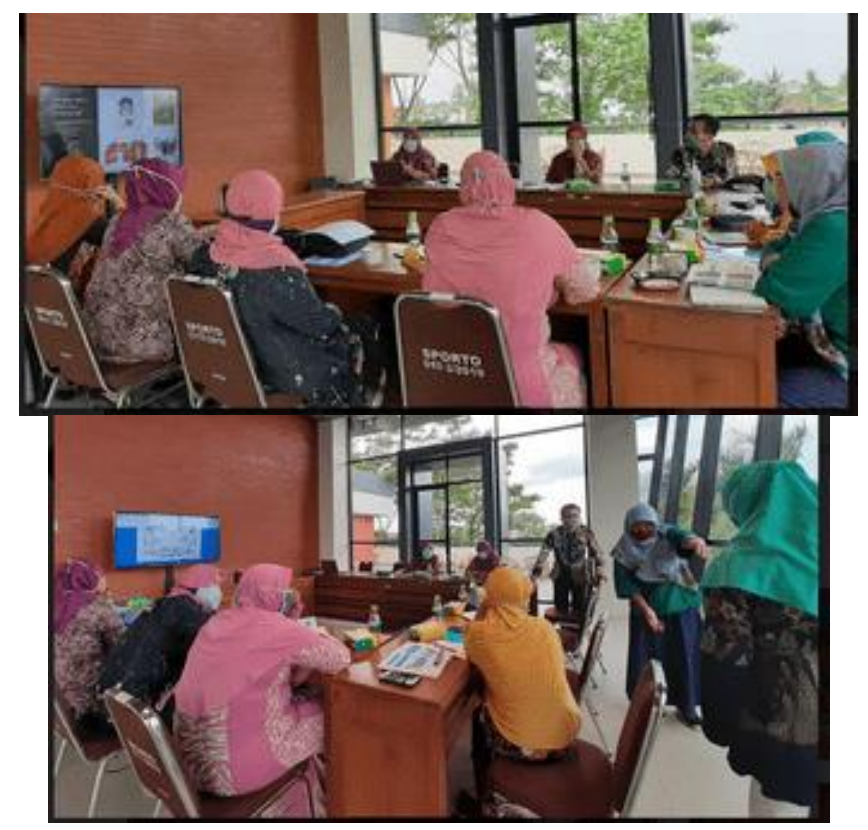

Gambar 3.1-2. Pelatihan atau pemberian materi "Seputar Pasien Pasca-TB, dan pengisian lembar investigasi

Evaluasi pengabdian masyarakat terhadap kader TB 'Aisiyah ditunjukkan dengan kelengkapan dan benarnya pengisian data dan cakupan data pasien pasca-TB di Kecamatan Mergangsan.

Tabel 2. Rekapitulasi Data dasar Pasien Pasca-TB oleh kader ‘Aisyiyah Kecamatan Mergangsan Agustus-September 2020

\begin{tabular}{|c|c|c|c|}
\hline No & Keterangan & Jumlah & Presentase \\
\hline \multirow[t]{5}{*}{1} & Umur (Depkes RI) & & \\
\hline & Remaja $17-25$ th & 9 & $16.67 \%$ \\
\hline & Dewasa $26-45$ th & 20 & $37.04 \%$ \\
\hline & Lansia $46-65$ & 22 & $40,74 \%$ \\
\hline & Manula $>65$ th & 3 & $5.55 \%$ \\
\hline \multirow[t]{3}{*}{2} & Jenis Kelamin & & \\
\hline & - Laki-laki & 30 & $55 ., 60 \%$ \\
\hline & - Perempuan & 24 & $44.40 \%$ \\
\hline \multirow[t]{8}{*}{3} & Pekerjaan & & \\
\hline & Tidak bekerja & 21 & $38.89 \%$ \\
\hline & Swasta & 19 & 35.19 \\
\hline & Buruh & 4 & $7.41 \%$ \\
\hline & Dagang & 3 & $5.55 \%$ \\
\hline & Guru & 1 & $1.85 \%$ \\
\hline & - Tukang becak & 2 & $3.70 \%$ \\
\hline & Pelajar & 4 & $7.41 \%$ \\
\hline \multirow[t]{7}{*}{4} & Pendidikan & & \\
\hline & $-\mathrm{SD}$ & 10 & $18.52 \%$ \\
\hline & - SMP & 18 & $33.33 \%$ \\
\hline & - SMA & 20 & $37.04 \%$ \\
\hline & - SMK / STM & 2 & $3.70 \%$ \\
\hline & - D3 & 1 & $1.85 \%$ \\
\hline & - SARJANA & 3 & $5.55 \%$ \\
\hline
\end{tabular}


Tabel 3. Rekapitulasi Gejala klinis pada pasien pasca-TB

\begin{tabular}{|c|c|c|c|c|c|}
\hline \multirow{2}{*}{$\begin{array}{l}\text { No } \\
1 \\
\end{array}$} & Keterangan & Jumlah & Presentase & & \\
\hline & \multicolumn{4}{|l|}{ Lama sembuh } & \\
\hline & $-1-5$ th & 19 & $35.19 \%$ & & \\
\hline & $-6-10$ th & 19 & $35.19 \%$ & & \\
\hline & $-11-20$ th & 12 & $22.22 \%$ & & \\
\hline & $->20$ th & 4 & $7.40 \%$ & & \\
\hline \multirow[t]{4}{*}{2} & Gejala klinis mulai & & & & \\
\hline & - tidak ada keluhan & 30 & $55.55 \%$ & & \\
\hline & - ada keluhan & 24 & $45.45 \%$ & & \\
\hline & & ya & tidak & ya & tidak \\
\hline 3 & Batuk & 6 & 48 & $11.11 \%$ & $88.89 \%$ \\
\hline 4 & Nyeri Dada & 3 & 51 & $5.56 \%$ & $94.44 \%$ \\
\hline 5 & Sesak nafas & 3 & 51 & $5.56 \%$ & $94.44 \%$ \\
\hline 6 & Mudah lelah & 17 & 37 & $31.48 \%$ & $68.52 \%$ \\
\hline 7 & Berat Badan turun & 20 & 34 & $37.04 \%$ & $62.96 \%$ \\
\hline 8 & Nafsu makan kurang & 4 & 50 & $7.41 \%$ & $92.59 \%$ \\
\hline 9 & Merokok & 7 & 47 & $13.00 \%$ & $87.00 \%$ \\
\hline 10 & DM & 5 & 49 & $9.26 \%$ & $90.74 \%$ \\
\hline 11 & Alkohol & 0 & 54 & $0 \%$ & $100 \%$ \\
\hline 12 & Lain-lain & 2 & 52 & $3.7 \%$ & $96.3 \%$ \\
\hline
\end{tabular}

Tabel. 4. Kondisi rumah dan lingkungan tempat tinggal

\begin{tabular}{|c|c|c|c|c|c|}
\hline $\begin{array}{l}\text { No } \\
1\end{array}$ & Keterangan & Jumlah & & Presentase & \\
\hline \multirow[t]{5}{*}{1} & \multicolumn{5}{|c|}{ Jumlah Penghuni Rumah } \\
\hline & $-1-4$ orang & 15 & & $27.78 \%$ & \\
\hline & $-5-8$ orang & 30 & & $55.55 \%$ & \\
\hline & ->9 orang & 9 & & $16.67 \%$ & \\
\hline & & ya & tidak & ya & tidak \\
\hline 2 & Rumah berdempetan & 47 & 7 & $87.00 \%$ & $13.00 \%$ \\
\hline 3 & Genting kaca & 34 & 20 & $63.00 \%$ & $37.00 \%$ \\
\hline 4 & Sirkulasi udara & 31 & 23 & $57.40 \%$ & $42.60 \%$ \\
\hline
\end{tabular}

Hasil Investigasi kader TB 'Aisyiyah terdiri 59 pasien pasca-TB dan lengkap sesuai lembar investigasi yang dibuat oleh tim dari FKIK UMY. Hal ini menunjukkan pengabdian masyarakat ini berhasil memberikan motivasi kepada kader TB 'Aisyiyah dan berhasil memberikan pengetahuan pentingnya evaluasi terhadap pasien pasca-TB. Pasien pasca-TB juga dengan sadar memberikan informasi kepada kader dengan berkomunikasi yang baik.

Hasil investigasi secara keseluruhan menunjukkan bahwa pasien pasca-TB di Kecamatan Mergangsan banyak pada usia dewasa dan lansia 42 orang (77.78\%), jumlah laki-laki lebih banyak dari perempuan $(55,60 \%)$, status pekerjaan kebanyakan tidak bekerja $38.89 \%$ serta berpendidikan SMP-SMA (70.37\%). Hal ini sesuai dengan beberapa referensi bahwa usia pasien TB terbanyak pada usia lansia (46-60 tahun). Usia ini merupakan usia bekerja atau produktif, tetapi faktor imunologi atau ketahanan tubuh sudah mulai berkurang. Pasca-TB banyak mengenai orang dengan pendidikan rendah, rata-rata SMP (Naomi, D.A et al, 2016)

Rata-rata pasien pasca-TB terbanyak dinyatakan sembuh 5 -10 tahun (70.38\%). Pasien mengalami keluhan sebanyak $45.45 \%$ dengan keluhan terbanyak mudah lelah dan berat badan turun masing-masing $31.48 \%$ dan $37.04 \%$. Jumlah penghuni dalam satu rumah pasien pasca-TB terbanyak 5-8 orang (55.55\%) dan $87.00 \%$ kondisi rumah berdempetan serta hampir $50 \%$ rumah dengan sirkulasi kurang baik dan tidak ada genting kaca.

Hasil temuan dari pengabdian masyarakat ini menunjukkan evaluasi pasien pasca-TB penting dilakukan, karena pada kelompok ini akan berisiko lebih tinggi relaps atau kambuh dibanding orang yang non-TB. Pasien mudah lelah dan nafsu makan menurun, hal ini selalu berkaitan dengan faktor ekonomi , kondisi lingkungan tempat tinggal yang berdempetan yang 
menyebabkan mudahnya penularan TB ini antara satu orang dengan orang yang lain. Sekuele atau gejala sisa pada jaringan paru akan mempengaruhi fungsi pernafasan yang tentunya akan sangat mengganggu aktivitas, sehingga pasien pasca-TB mudah lelah, mudah capai Naomi, D.A et al, 2016; Tarigan et al., 2018)

\section{Simpulan}

Data yang diperoleh kader TB 'Aisyiyah penting sebagai informasi gejala klinis, kondisi rumah dan lingkungan pasien pasca-TB. Gejala klinis terbanyak pada pasien pasca-TB di Kecamatan Mergangsan adalah nafsu makan menurun dan mudah capai. Kondisi rumah yang berdempetan, penggunaan genting kaca dan sirkulasi udara yang kurang baik menjadi wacana dan pemikiran stakeholder Kecamatan Mergangsan untuk mencari solusi pengentasannya. Peran kader TB 'Aisyiyah sebagai mediator sangat efektif dan perlu dioptimalkan dengan berbagai kegiatan yang dapat meningkatkan motivasi seperti refreshing ilmu, diskusi, pelatihan dan pemberian reward sebagai stimulus yang dapat meningkatkan kinerja kader

\section{Ucapan Terima Kasih}

Kami ucapkan terimakasih kepada LP3M UMY sebagai pemberi dana, kader TB 'Aisyiyah, Kepala Desa dan Puskesmas Mergangsan yang telah berpartisipasi aktif, sehingga pengabdian masyarakat ini dapat berjalan dengan baik di tengah Pandemi Covid-19.

\section{Daftar Pustaka}

Adriztina, I., Adnan, A., Hajar, S., Parluhutan, H., Sorimuda, S., Ilmu, B., Telinga, K., Kepala, H. T., Fk, L., \& Pulmonologi, D. (2016). Gangguan Pendengaran dan Keseimbangan pada Penderita Tuberkulosis yang Mendapat Pengobatan Antituberkulosis Kategori 1 dan 2 Hearing and Balance Impairment in Tuberculosis Patient with Category 1 st and 2 nd Antituberculosis Treatment. 17.

Afifa, J., Pakasi, T.A., 2015. Uji Jalan 6 Menit pada Pasien Pasca-TB Paru dan Hubungannya dengan Gejala Klinis TB Serta Gambaran Foto X-Ray Toraks di Kabupaten Timor Tengah Selatan Nusa Tenggara Timur 18.

Chrysantina, A., Kusnanto, H., Fuad, A., n.d. Analisis spasial dan temporal kasus tuberkulosis di Kota Yogya, Juli - Desember 2004.

Data Dinas kesehatan Yogyakarta 2018 (8).

Fadhilah, N., Nuryati, E., Duarsa, A., Djannatun, T., Hadi, R.S., 2014. Perilaku Kader dalam Penemuan Suspek Tuberkulosis. Kesmas: National Public Health Journal 280. https://doi.org/10.21109/kesmas.v0i0.381

Hugo, B., Ngahane, M., Nouyep, J., Nganda, M., Mapoure, Y., Wandji, A., Endale, M., \& Afane, E. (2016). Post-tuberculous lung function impairment in a tuberculosis reference clinic in Cameroon. Respiratory Medicine, 114, 67-71. https://doi.org/10.1016/j.rmed.2016.03.007

Kunci - Management of Relapsed Lung Tuberculosis Case of A.pdf, n.d.

Mbatchou Ngahane, B.H., Nouyep, J., Nganda Motto, M., Mapoure Njankouo, Y., Wandji, A., Endale, M., Afane Ze, E., 2016. Post-tuberculous lung function impairment in a tuberculosis reference clinic in Cameroon. Respiratory Medicine 114, 67-71. https://doi.org/10.1016/j.rmed.2016.03.007

Naomi, D.A., Dilangga, P., Ramadhian, M.R., Marlina, N., 2016. Penatalaksanaan Tuberkulosis Paru Kasus Kambuh pada Wanita Usia 32 Tahun di Wilayah Rajabasa.

Pasaribu, R., 2018. Fakultas Kesehatan Masyarakat Universitas Sumatera Utara Medan. 
Riyadi, I., 2018. Analisis Strategi Komunikasi Community TB-HIV Care 'Aisyiyah Dalam Pendampingan Pasien TB-MDR di RSUD Labuang Baji Makassar .

Situasi TBC di Indonesia 2018. https://www.tbindonesia.or.id/page/view/11/situasi-tbc-diindonesia

TB Kemenkes 2018.Kasus TBC Turun 200 Ribu

Tarigan, A.P., Pandia, P., Eyanoer, P., Tina, D., Pratama, R., Fresia, A., Tamara, Silvanna, 2018. Obstructive lung disease as a complication in post pulmonary TB. IOP Conference Series: Earth and Environmental Science 125, 012154. https://doi.org/10.1088/1755$1315 / 125 / 1 / 012154$

Utara, U. S., Utara, U. S., \& Utara, U. S. (2018). Peran Organisasi Aisyiyah dalam penanggulangan TB di Kota Medan 